\title{
Assessing Guest Selectivity within Metallacrown Host Compartments
}

\author{
Choong-Sun Lim, ${ }^{[a]}$ Annabel Cutland Van Noord, ${ }^{[a]}$ Jeff W. Kampf, ${ }^{[a]}$ and \\ Vincent L. Pecoraro*[a]
}

Keywords: Molecular compartment / Metallacrown / Selective recognition / Host-guest chemistry

\begin{abstract}
15-MC-5 complexes associate in the solid state to form chiral compartments capable of binding guests. Using small molecular yardsticks, we are able to assess the size restrictions of these structures. Dicarboxylate guests that are too short to span the $\mathrm{Gd}^{\mathrm{III}}$ ions are stabilized by solvates that hydrogen bond to the uncoordinated carboxylate, while guests that are
\end{abstract}

too long destroy the weakly associated structure. We also demonstrate that all that is required for guest encapsulation is unsaturation of the chain connection carboxylates rather than necessitating the presence of aromaticity.

(@ Wiley-VCH Verlag GmbH \& Co. KGaA, 69451 Weinheim, Germany, 2007)

\section{Introduction}

In 1989, we described the concept of building metallamacrocycles ${ }^{[1-3]}$ using the metallacrown analogy ${ }^{[4]}$ These early analogs of crown ethers, ${ }^{[5,6]}$ which have $\mathrm{M}-\mathrm{N}-\mathrm{O}$ connectivity instead of the $\mathrm{O}-\mathrm{C}-\mathrm{C}$ repeat unit of a crown ether, were often planar, containing a site for cation binding in a central cavity and a surface upon which anions could be appended. ${ }^{[7,8]}$ Subsequently, chiral $15-\mathrm{MC}-5$ complexes, ${ }^{[9]}$ adorned with aromatic groups, were shown to form molecular compartments ${ }^{[10-13]}$ in the solid state. These compartments are reminiscient of the cryptatoclathrates described by Saalfrank $\cdot{ }^{[14]}$ Metallacrowns made exclusively with $(R)$ or $(S)$-phenylalaninehydroxamic acid form metallamacrocycles having a hydrophobic face surrounded by five benzyl groups that generate a cavity for a guest and a much less sterically encumbered hydrophilic face. ${ }^{[15]}$ Previous solution studies have demonstrated that these 15-MC-5 structures are stable in solution when $\mathrm{Ln}^{\mathrm{III}}$ ions are present. ${ }^{[7,9,16]}$ When crystals are grown from water, the phenyl groups from the two metallacrowns contact one another like two folded hands, hence we call this form the hands structure. In contrast, crystals prepared from methanol/water mixtures lead to a different "polymorph" in which the metallacrowns form helices with microporous channels rather than compartments. ${ }^{[17]}$ In the hands polymorph, the hydrophobic faces of two metallacrowns associate, forming a compartment in which a guest is sequestered. ${ }^{[11,13]}$ Of significant interest, aliphatic carboxylates are generally excluded from this compartment and bind solely to the hydrophilic face of the metallacrowns while, in contrast, aromatic carboxylic acids can be confined within this aromatic rich

[a] Department of Chemistry and Biophysics Research Division, The University of Michigan,

Ann Arbor, Michigan 48109-1055, USA

Fax: +1-17349367628

E-mail: vlpec@umich.edu environment. ${ }^{[11,13]}$ Thus, succinate or adipate have never been observed within the compartment, whereas terephthalate binds to this site preferentially.

\section{Discussion and Results}

The ability to exploit the size and chemical nature of organic dicarboxylates to discriminate guest binding is a desirable design concept. We have been interested in assessing whether an aromatic ring is an essential feature allowing access of the guest into the compartments hydrophobic cavity or whether simple unsaturation within the backbone is sufficient for cavity recognition.

Furthermore, we felt that it was prudent to use rigid molecules of varying length as molecular yardsticks that would determine to what extent the cylinder's long axis could be stretched in order to accommodate a dicarboxylate guest. In this report, we demonstrate that the presence of even one double bond allows the guest to insert within the compartment. We also show that when phenylalaninehydroxamic acid is used to form the host, there is a narrow range of acceptable lengths for guests to span the compartment.

We have chosen the well characterized $\mathrm{Gd}\left(\mathrm{NO}_{3}\right)_{3}[15-$ $\mathrm{MC}_{\mathrm{L}-\mathrm{pheHA}} \mathrm{5}^{[]^{[1]}}$ as our host for these studies and we selected four different guest molecules (Scheme 1) to determine which physical properties of guests are required for a good fit within the compartments. Because carboxylates may bind to metals in an endo,exo or bidentate manner, ${ }^{[18]}$ we have provided lengths for these molecules which are measured between the carboxylate carbon atoms rather than to the oxygen atoms. All four compounds have double bonds as well as carboxylate moieties at each end resulting in their binding to the gadolinium of each metallacrown toward the hydrophobic face. ${ }^{[19-22]}$ 

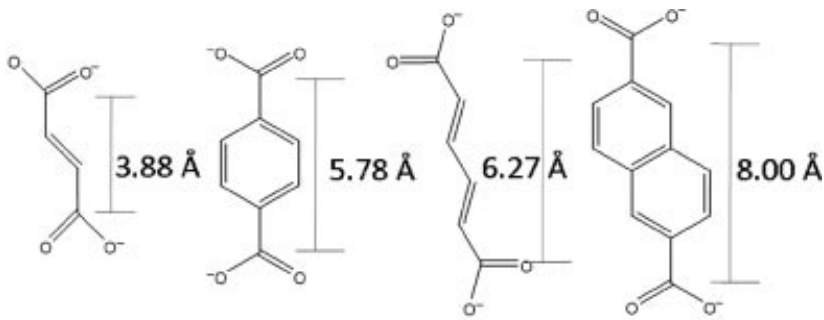

fumarate terephthalate 1 2 muconate 3

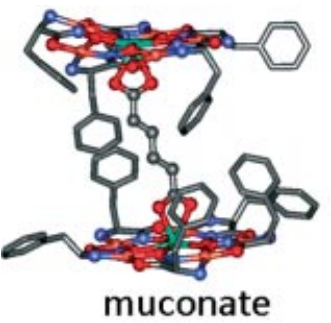

naphDC 4
Scheme 1. Guest molecules bound to hydrophobic site of metallacrown (3: trans,trans-muconate, 4: 2,6-naphthalenedicarboxylate).

By using X-ray diffraction studies, we observed that the terephthalate and trans,trans-muconate guests (with $\mathrm{C}-\mathrm{C}$ bond lengths of $5.8 \AA$ and $6.3 \AA$, respectively) connect two metallacrowns across the hydrophobic faces. ${ }^{[23]}$ Each of the carboxylate groups bind to the $\mathrm{Gd}^{\mathrm{III}}$ in an endo,endo-1,3bidentate fashion. These structures are shown in Figure 1. The Gd-Gd distances between the two metallacrowns are ca. $11.6 \AA$ for both the muconate and terephthalate structures (Figure 2 and Table 1). Furthermore, the two metallacrowns are stacked nearly on top of one another with only a $2-5^{\circ}$ tilt angle and are slipped to one side by only $7-10^{\circ}$. This observation suggests that the metallacrowns are ideally oriented, and that there are strong interactions between the phenyl groups of the two metallacrowns composing the compartment. In addition, two phenyl groups of the metallacrowns make hydrophobic contacts with the phenyl ring of the guest. Because both the terephthalate metallacrown and muconate metallacrown have similar structures, the formation of compartments is not affected by the difference in steric bulk of the two guests. The fact that muconate is found within the hydrophobic cavity demonstrates that aromaticity is not an essential feature for guest recognition as the two double bonds of this molecule apparently are sufficient to drive it into the interior of the capsule.

The shorter and longer dicarboxylates that were examined illustrate the length restriction for guests within the capsule. Fumarate has the shortest length (3.88 $\AA$ ) between the two $\alpha$-carbon atoms of the dicarboxylates. As shown in Figure 1, fumarate with a single double bond is still able to insert within the compartment; however, it is too short to span the two central Gd ions. This is even true given that fumarate adopts a monodentate, endo coordination mode which acts to extend the length of the molecule as compared to the bidentate geometries observed for muconate and terephthalate.

The fumarate is stabilized within the compartment by forming a hydrogen bond to a water molecule that is bound to the $\mathrm{Gd}^{\mathrm{III}}$ of the second metallacrown. Clearly, the compartment with bound fumarate is highly distorted. While the $\mathrm{Gd}-\mathrm{Gd}$ distance shortens to $11.2 \AA$, the orientation of the two metallacrown rings is greatly perturbed. In particular, the $\mathrm{Gd}^{\mathrm{III}}$ of the top metallacrown is shifted over $6 \AA$ with respect to the $\mathrm{Gd}^{\mathrm{III}}$ of the bottom metallacrown, whereas the corresponding orientation for muconate and

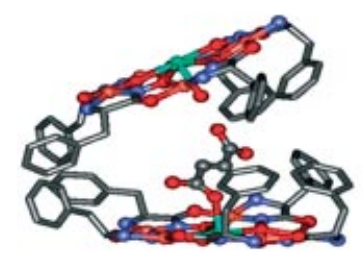

fumarate
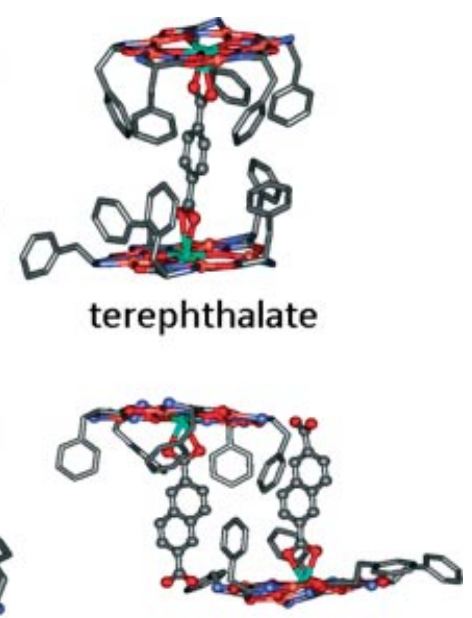

naphDC
Figure 1. Structure of muconate-MC and terephthalate-MC show molecular compartments. However, fumarate-MC and 2,6-naphthalenedicarboxylate-MC do not form compartments. Guests on the hydrophilic sites of both metallacrowns of all compartments were omitted. ${ }^{[23]}$

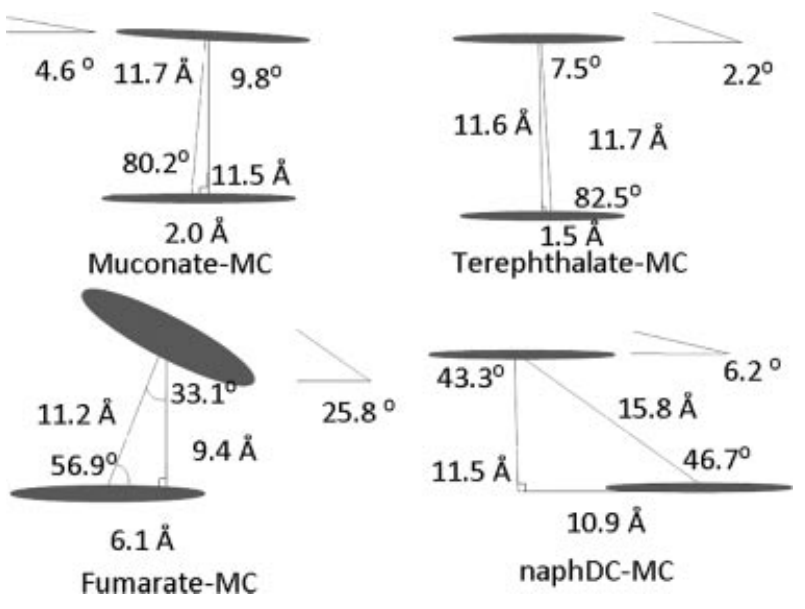

Figure 2. Diagram which shows bonding distance and angles between metallacrown and each guest compound in the crystal structure.

Table 1. Distances and angles of each guest to metallacrowns.

\begin{tabular}{|c|c|c|c|c|c|}
\hline \multirow{3}{*}{8} & & fumarate & $\begin{array}{l}\text { Terephth- } \\
\text { alate }\end{array}$ & Muconate & NaphDC \\
\hline & A & $11.2 \AA \nexists$ & $11.7 \AA ̊$ & $11.7 \AA ̊$ & $15.8 \AA ̊$ \\
\hline & B & $9.4 \AA \AA$ & $11.6 \AA$ & $11.5 \AA$ & $11.5 \AA$ \\
\hline & C & $6.1 \AA ̊$ & $1.5 \AA$ & $2.0 \AA$ & $10.9 \AA$ \\
\hline & $\beta$ & $56.9^{\circ}$ & $82.5^{\circ}$ & $80.2^{\circ}$ & $46.7^{\circ}$ \\
\hline & $\gamma$ & $33.1^{\circ}$ & $7.5^{\circ}$ & $9.8^{\circ}$ & $43.3^{\circ}$ \\
\hline & $\delta$ & $25.8^{0}$ & $2.2^{0}$ & $4.6^{\circ}$ & $6.2^{\circ}$ \\
\hline
\end{tabular}

A: distance between two centers of the planes B: the closest distance between a center of one plane to the other plane C: shifted distance of a metallacrown to the other one $\delta$ : angle between two planes 
terephthalate structures is $2 \AA$ or less. This shift of the metallacrown centroids cause a marked slippage $\left(33^{\circ}\right)$ and tilting $\left(26^{\circ}\right)$ of the metallacrown rings as shown in Figure 2. All of these changes lead to a distorted and opened compartment.

While shortening the guest length causes major reorientation of the $[\mathrm{Gd}(15-\mathrm{MC}-5)]_{2}$ compartment, inclusion of naphthalenedicarboxylate as a guest, which has the longest distance ( $8 \AA$ ) between two $\alpha$-carbon atoms, completely destroys the compartment structure. The distance between the two $\alpha$-carbon atoms of naphthalenedicarboxylate is sufficient to connect the two metallacrowns. However, doing so prevents the phenyl groups of the hosts from interacting well with one another by pushing the two metallacrowns far away. The absence of the $\pi-\pi$ interactions between these rings diminishes the stability of the compartment leading to a solid with individual naphthalenedicarboxylates bound to metallacrowns rather than forming compartments using the hands structure. Figure 1 illustrates that the naphthalenedicarboxylate binds to $\mathrm{Gd}^{\mathrm{III}}$ as an endo,endo-1,3-bidentate chelate; however, another metallacrown is unavailable to bind the second carboxylate group. The result is that the closest $\mathrm{Gd}-\mathrm{Gd}$ distance is over $15 \AA$ and the metallacrown rings are slid almost $11 \AA$ with respect to one another. Interestingly, because the two metallacrowns are no longer constrained to form a compartment, the tilt angle between adjacent, noninteracting metallacrowns at $6.2^{\circ}$ is more similar to muconate and terephthalate systems then the fumarate complex.

\section{Conclusion}

A structural analysis of $[\mathrm{Gd}(15-\mathrm{MC}-5)]_{2}{ }^{6+}$ compartments demonstrates that there is a narrow cylinder length that will accommodate a guest. For rigid ligands containing two carboxylates the length appears to be ca. $11.5 \AA$. Significantly shorter or longer guests perturb the compartment integrity and, in the case of guests that are too long, will completely disrupt the compartment from forming. These observations are useful for designing a second generation of metallacrown based compartments that will be able to bind longer guests with the ultimate objective of carrying out regio- or stereoselective transformations within the cavity of these supramolecular complexes. We conclude that longer guests such as 2,6-naphthalenedicarboxylate would be better able to fit into the hydrophobic site using extended aromatic side chains rather than the L-phenylalaninehydroxamic acid to form metallacrown compartments. In contrast, $\mathrm{Gd}\left(\mathrm{NO}_{3}\right)$ ${ }_{3}\left[15-\mathrm{MC}_{\mathrm{L}-\mathrm{pheHA}}-5\right]$ complex appears perfect for guests such as muconate or terephthalate.

\section{Experimental Section}

All reagents were purchased from Aldrich and used without further purification. $\mathrm{Gd}\left(\mathrm{NO}_{3}\right)_{3}\left[15-\mathrm{MC}_{\mathrm{L}-\mathrm{pheHA}^{-5}}{ }^{-5}\right.$ was prepared by the method published in ref. ${ }^{[1]}$

Reaction of 1 with $\mathbf{G d}\left(\mathrm{NO}_{3}\right)_{3}\left[\mathbf{1 5}-\mathbf{M C}_{\mathbf{L}-\text { pheHA }}-\mathbf{5}\right.$ ]: $\mathrm{Gd}\left(\mathrm{NO}_{3}\right)_{3}[15-$ $\mathrm{MC}_{\mathrm{L} \text {-pheHA}}-5$ ] (30 mg, $\left.0.019 \mathrm{~mol}\right)$ and $1(9.1 \mathrm{mg}, 0.057 \mathrm{~mol})$ reacted in water, and enough methanol was added to dissolve all products that formed yielding a water/methanol mixture of ratio 1:2. The solution was slowly evaporated to get single crystal for X-ray diffraction.

Reaction of 2 with $\mathbf{G d}\left(\mathrm{NO}_{3}\right)_{3}\left[\mathbf{1 5}-\mathrm{MC}_{\mathbf{L}-\mathrm{pheHA}}-\mathbf{5}\right]$ : $\mathrm{Gd}\left(\mathrm{NO}_{3}\right)_{3}[15-$ $\mathrm{MC}_{\mathrm{L} \text {-pheHA }}$-5] (30 mg, $\left.0.019 \mathrm{~mol}\right)$ and $2(12 \mathrm{mg}, 0.057 \mathrm{~mol})$ reacted in water/methanol (1:2). Crystals were grown by slow evaporation.

Reaction of 3 with $\mathbf{G d}\left(\mathrm{NO}_{\mathbf{3}}\right)_{\mathbf{3}}\left[\mathbf{1 5}-\mathbf{M C}_{\mathbf{L - p h e H A}} \mathbf{- 5}\right]$ : $\mathrm{Gd}\left(\mathrm{NO}_{3}\right)_{3}[15-$ $\mathrm{MC}_{\mathrm{L} \text {-pheHA}}{ }^{-5}$ ] (30 mg, $\left.0.019 \mathrm{~mol}\right)$ and $3(8.1 \mathrm{mg}, 0.057 \mathrm{~mol})$, which had been neutralized with $1 \mathrm{~N} \mathrm{NaOH}$, reacted in water/methanol (1:2). Crystals were grown by slow evaporation.

Reaction of 4 with $\mathbf{G d}\left(\mathrm{NO}_{3}\right)_{3}\left[\mathbf{1 5}-\mathbf{M C}_{\mathbf{L}-\mathrm{pheHA}} \mathbf{- 5}\right.$ ]: $\mathrm{Gd}\left(\mathrm{NO}_{3}\right)_{3}[15-$ L-pheHA $^{-5}$ ] (30 mg, $\left.0.019 \mathrm{~mol}\right)$ and $4(17 \mathrm{mg}, 0.057 \mathrm{~mol})$ reacted in water/methanol (1:2). Crystals were grown by slow evaporation.

CCDC-635552 to -635554 contain the supplementary crystallographic data for this paper. These data can be obtained free of charge from The Cambridge Crystallographic Data Centre via www.ccdc.cam.ac.uk/data_request/cif.

\section{Acknowledgments}

We thank the National Science Foundation for supporting this research (CHE-0111428).

[1] M. S. Lah, M. L. Kirk, W. Hatfield, V. L. Pecoraro, J. Chem. Soc., Chem. Commun. 1989, 1606-1608.

[2] M. S. Lah, V. L. Pecoraro, J. Am. Chem. Soc. 1989, 111, 72587259.

[3] V. L. Pecoraro, Inorg. Chim. Acta 1989, 155, 171-173.

[4] V. L. Pecoraro, A. J. Stemmler, B. R. Gibney, J. J. Bodwin, H. Wang, J. W. Kampf, A. Barwinski, in Progress in Inorganic Chemistry, vol. 45 (Ed.: K. D. Karlin), John Wiley and Sons, Inc., New York, 1997, pp. 83-177.

[5] C. J. Pedersen, J. Am. Chem. Soc. 1967, 89, 2495-2496.

[6] C. J. Pedersen, J. Am. Chem. Soc. 1967, 89, 7017-7036.

[7] A. J. Stemmler, J. W. Kampf, M. L. Kirk, B. H. Atasi, V. L. Pecoraro, Inorg. Chem. 1999, 38, 2807-2817.

[8] B. R. Gibney, D. P. Kessissoglou, J. W. Kampf, V. L. Pecoraro, Inorg. Chem. 1994, 33, 4840-4849.

[9] A. J. Stemmler, A. Barwinski, M. J. Baldwin, V. Young, V. L. Pecoraro, J. Am. Chem. Soc. 1996, 118, 11962-11963.

[10] J. Rebek, Angew. Chem. Int. Ed. 2005, 44, 2068-2078.

[11] A. D. Cutland, J. A. Halfen, J. W. Kampf, V. L. Pecoraro, J. Am. Chem. Soc. 2001, 123, 6211-6212.

[12] D. J. Cram, Angew. Chem. Int. Ed. Engl. 1991, 30, 1024-1027.

[13] G. Mezei, J. W. Kampf, V. L. Pecoraro, Chem. Commun. 2006, in press.

[14] R. W. Saalfrank, R. Harbig, J. Nachtrab, W. Bauer, K.-P. Zeller, D. Stalke, M. Teichert, Chem. Eur. J. 1996, 2, 1363-1367.

[15] A. D. Cutland, R. G. Malkani, J. W. Kampf, V. L. Pecoraro, Angew. Chem. Int. Ed. 2000, 39, 2689-2691.

[16] M. Careri, F. Dallavalle, M. Tegoni, I. Zagnoni, J. Inorg. Biochem. 2003, 93, 174-180.

[17] A. C. Cutland-Van Noord, J. W. Kampf, V. L. Pecoraro, Angew. Chem. Int. Ed. 2002, 41, 4667-4670.

[18] R. L. Rardin, W. B. Tolman, S. J. Lippard, New J. Chem. 1991, $15,417-430$.

[19] Crystal data for $\left[1-\mathrm{Gd}\left(\mathrm{NO}_{3}\right)_{3}\left[15-\mathrm{MC}_{\mathrm{L}-\mathrm{pheHA}}-5\right]\right.$ : $\left[\mathrm{C}_{102} \mathrm{H}_{155} \mathrm{Cu}_{10} \mathrm{Gd}_{2} \mathrm{~N}_{20} \mathrm{O}_{58}\right], M=3521.34$, Monoclinic, space group $P 2$ (1) (no. 4), $a=14.756(2), b=33.580(5), c=15.403(2)$, $a=90, \beta=118.573(2), \gamma=90, V=6702.8(16) \AA^{3}, Z=2 ; \rho_{\text {calcd. }}$. $=1.754 \mathrm{~g} / \mathrm{cm}^{3}$; crystal dimensions, $0.42 \times 0.22 \times 0.20 \mathrm{~mm}^{3} ; \mu=$ $2.624 \mathrm{~mm}^{-1} ; T=113(2) \mathrm{K} ; 86931$ reflections $\left(R_{\text {int }}=0.0385\right)$, 32862 independent reflections and 31839 reflections $[I>2 \sigma(I)]$, 
for all data $R_{1}=0.0510, w R_{2}=0.1149$, for observed data $[I>2 \sigma(I)] R_{1}=0.0487, w R_{2}=0.1137$

[20] Crystal data for $2-\mathrm{Gd}\left(\mathrm{NO}_{3}\right)_{3}\left[15-\mathrm{MC}_{\mathrm{L}-\mathrm{pheHA}^{-5}}\right.$ ]: See ref. ${ }^{[11]}$.

[21] Crystal data for 3- $\mathrm{Gd}\left(\mathrm{NO}_{3}\right)_{3}\left[15-\mathrm{MC}_{\mathrm{L}-\text { pheHA }}-5\right]$ : $\left[\mathrm{C}_{108} \mathrm{H}_{164.82^{-}}\right.$ $\left.\mathrm{Cu}_{10} \mathrm{Gd}_{2} \mathrm{~N}_{22} \mathrm{O}_{63.41}\right], M=3735.90$, triclinic, space group $P 1$ (no. 1), $a=14.828(4), b=15.730(4), c=16.535(5), \alpha=102.277(5)$, $\beta=101.471(5), \gamma=96.683(5), V=3642.3(17) \AA^{3}, Z=1 ; \rho_{\text {calcd }}$ $=1.703 \mathrm{~g} / \mathrm{cm}^{3}$; crystal dimensions, $0.40 \times 0.20 \times 0.10 \mathrm{~mm}^{3} ; \mu=$ $2.423 \mathrm{~mm}^{-1} ; T=123(2) \mathrm{K} ; 38960$ reflections $\left(R_{\mathrm{int}}=0.0187\right)$, 31446 independent reflections and 30606 reflections $[I>2 \sigma(I)]$, for all data $R_{1}=0.0306, w R_{2}=0.0772$, for observed data $[I>2 \sigma(I)] R_{1}=0.0295, w R_{2}=0.0764$.

[22] Crystal data for $4-\mathrm{Gd}\left(\mathrm{NO}_{3}\right)_{3}\left[15-\mathrm{MC}_{\mathrm{L}-\text { pheHA }}-5\right]$ : $\left[\mathrm{C}_{135} \mathrm{H}_{184^{-}}\right.$ $\left.\mathrm{Cu}_{10} \mathrm{Gd}_{2} \mathrm{~N}_{20} \mathrm{O}_{56}\right], M=3932.92$, monoclinic, space group $P 2(1)$ (no. 4), $a=17.110(2), b=29.032(4), c=17.202(2), a=90, \beta$ 103.673(6), $\gamma=90, V=8303(2) \AA^{3}, Z=2 ; \rho_{\text {calcd. }}=1.573 \mathrm{~g} / \mathrm{cm}^{3}$; crystal dimensions, $0.50 \times 0.40 \times 0.32 \mathrm{~mm}^{3} ; \mu=2.127 \mathrm{~mm}^{-1} ; T$ $=118(2) \mathrm{K} ; 88356$ reflections $\left(R_{\text {int }}=0.0375\right), 40705$ independent reflections and 36609 reflections $[I>2 \sigma(I)]$, for all data $R_{1}=0.0568, w R_{2}=0.1369$, for observed data $[I>2 \sigma(I)] R_{1}=$ $0.0497, w R_{2}=0.1333$.

[23] In all structures, solvent waters and/or monodentate bound guests occupy the $\mathrm{Gd}^{\mathrm{III}}$ sites on the hydrophilic face.

Received: December 12, 2006 Published Online: February 26, 2007 